
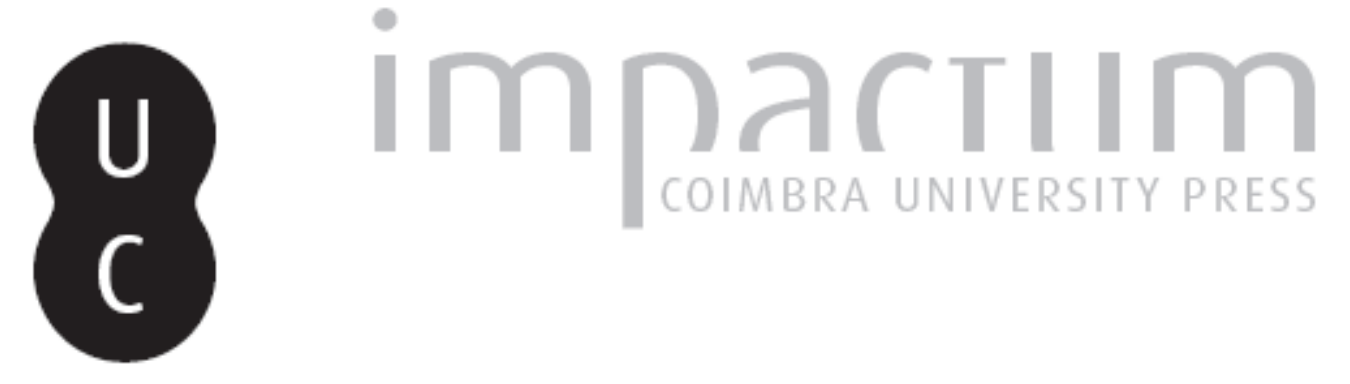

\title{
As mudanças no uso do solo e o risco de desertificação: o exemplo de Marrocos
}

\author{
Autor(es): $\quad$ Coelho, C.O.A.; Laouina, A.; Ferreira, A.J.D.; Chaker, M.; Naciri, R.; \\ Naafa, R.; Boulet, A.K.
}

Publicado por: Associação Portuguesa de Riscos, Prevenção e Segurança

URL persistente:

URI:http://hdl.handle.net/10316.2/40111

DOI:

DOI:https://doi.org/10.14195/1647-7723_7_4

Accessed : $\quad$ 26-Apr-2023 15:39:19

A navegação consulta e descarregamento dos títulos inseridos nas Bibliotecas Digitais UC Digitalis, UC Pombalina e UC Impactum, pressupõem a aceitação plena e sem reservas dos Termos e Condições de Uso destas Bibliotecas Digitais, disponíveis em https://digitalis.uc.pt/pt-pt/termos.

Conforme exposto nos referidos Termos e Condições de Uso, o descarregamento de títulos de acesso restrito requer uma licença válida de autorização devendo o utilizador aceder ao(s) documento(s) a partir de um endereço de IP da instituição detentora da supramencionada licença.

Ao utilizador é apenas permitido o descarregamento para uso pessoal, pelo que o emprego do(s) título(s) descarregado(s) para outro fim, designadamente comercial, carece de autorização do respetivo autor ou editor da obra.

Na medida em que todas as obras da UC Digitalis se encontram protegidas pelo Código do Direito de Autor e Direitos Conexos e demais legislação aplicável, toda a cópia, parcial ou total, deste documento, nos casos em que é legalmente admitida, deverá conter ou fazer-se acompanhar por este aviso.

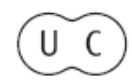




\title{
As mudanças no uso do solo e o risco de desertificação: o exemplo de Marrocos
}

\author{
Coelho, C.O.A.*, Laouina, A.**, Ferreira, A.J.D. ${ }^{*}$, Chaker, M. ${ }^{* *}$, Naciri, R. ${ }^{* *}$, Naafa, R. ${ }^{* *}$ \& Boulet, A.K. *
}

\begin{abstract}
Resumo:
Neste artigo analisanı-se os processos hidrológicos e erosivos conducentes à degradação do solo e desertificação nas áreas de Ksar El Kebir (Alcácer Quibir) e Ben Slimane no Norte de Marrocos, áreas sujeitas a mudanças no uso do solo e a pressões demográficas significativas.

Palavras chave:

Marrocos, erosão de solos, desertificação.

Résumé:

Cet article analyse les processus hydrologiques et érosifs conduisant à la dégradation du sol et à la désertification dans les régions de Ksar El Kebir et Ben Slimane, au Nord du Maroc, régions qui souffrent des changements d'usage du sol et des pressions démographiques importantes.

Mots clés:

Maroc, érosion des sols, désertification.

Abstract:

The aim of this article is to analyse hydrological and erosive processes leading to soil degradation and desertification in the regions of Ksar El Kebir and Ben Slimane, Northern Morocco, regions that are suffering land use changes and important demographic pressures.

Key words:

Morocco, soil erosion, desertification.
\end{abstract}

\section{Introdução}

A degradação da vegetação e dos solos no Norte de África tem origens remotas, inscrevendo-se num processo que tem vindo a reduzir drasticamente as áreas de florestas e matos, especialmente as que se situam em áreas marginais, não propícias à agricultura. Neste processo, a queima, o corte e sobretudo o sobrepastoreio estão a dizimar completamente as áreas de floresta. Mercê dos constrangimentos socio-económicos, a pressão sobre os solos é manifestamente excessiva,

\footnotetext{
*_"Centro das Zonas Costeiras e do Mar", Departmento de Ambiente e Ordenamento, Universidade de Aveiro, P-3810-193 Aveiro, Portugal Phone:+351234370397,Fax: +351234429290, E-mail:coelho@dao.ua.pt

*** - Laboratoire de geomorphologie, Faculté des Lettres et Sciences Humaines, Université Mohamed V, BP 2122 Ryad, 10104 Rabat, Morocco. Phone+2127771893,Fax:+2127772068,E-mail:cugnod@acdim.net.ma
}

verificando-se a utilização de técnicas de maneio e de usos de solo pouco apropriados à fragilidade do solo.

A população humana triplicou no período de 1950 e 1990 na Tunísia, Argélia e Marrocos prevendose que o número de cabeças de gado tenha aumentado em proporção idêntica, o que representa uma carga extraordinária sobre as áreas não agricultadas. As culturas de cereais há muito que ocupam solos marginais de forma a tentar alimentar a população crescente. Nestas áreas a prática secular do pousio está hoje confinada a cerca de $30 \%$ das terras. Esta dinâmica acarreta aumentos consideráveis da erosão e degradação dos solos que se chegam a traduzir no aparecimento de ravinamentos e no assoreamento das albufeiras (LAOUINA, 1999).

Este estudo enquadra-se no projecto MEDCHANGE - "Os efeitos das mudanças no uso da terra e nas 
técnicas de maneio em sistemas agro-silvo-pastoris, sobre os processos de degradação do solo"(1) financiado pela Comunidade Europeia, no âmbito do programa INCO-DC.

Ele assenta numa metodologia holística, que associa informação ambiental e socio-económica com vista a atingir os objectivos seguintes: (i) investigar as alterações ao nível da degradação dos solos, devidas a mudanças no uso do solo, em áreas marginais no Mediterrâneo Ocidental, nomeadamente no Norte da África (Marrocos e Tunísia) e na Península Ibérica; (ii) identificar as tendências actuais e futuras da evolução, do uso e das técnicas de gestão do solo, relativamente à orientação geral das políticas sócioeconómicas regionais e nacionais.

Neste artigo analisam-se os processos hidrológicos e erosivos conducentes à degradação do solo e desertificaçãoem duas áreas de Marrocos, sujeitas a mudanças no uso e a pressões demográficas significativas.

\section{Área de estudo}

O quadro 1 apresenta as características gerais das áreas de Ksar El Kebir e Ben Slimane no Norte de Marrocos.

\section{Ksar El Kebir (Alcácer Quibir)}

Esta região situa-se nas planuras do Sudoeste da Cordilheira do Rift ocidental.É constituída essencialmente por uma linha de cristas baixas e descontínuas em calcários e margas, orientada de Sudeste a Noroeste, formada por outeiros com altitude compreendida entre os 80 e os 300 metros (Fotos 1 e 2).

Os solos são pobres, pouco espessos e bastante argilosos. Situada no andar bio-climático sub-húmido e beneficiando das influências atlânticas, a região recebe em média, entre 600 e $800 \mathrm{~mm}$ de chuva, distribuída por 60 a 80 dias por ano, enquanto nos cumes do Rift a chuva ultrapassa os $2000 \mathrm{~mm}$ anuais.

Quadro 1 - Áreas de estudo

\begin{tabular}{ccccc}
\hline $\begin{array}{c}\text { Áreas de } \\
\text { estudo }\end{array}$ & $\begin{array}{c}\text { Coordenadas } \\
\text { geográficas }\end{array}$ & $\begin{array}{c}\text { Precipitação } \\
\text { média anual } \\
(\mathrm{mm})\end{array}$ & $\begin{array}{c}\text { Uso do solo } \\
\text { dominante }\end{array}$ & $\begin{array}{c}\text { Formas de } \\
\text { degradação do solo } \\
\text { dominantes }\end{array}$ \\
\hline $\begin{array}{c}\text { Ksar El Kebir } \\
\text { (Alcacer Quibir) }\end{array}$ & $\begin{array}{c}34^{\circ} 59^{\prime} \mathrm{N} \\
05^{\circ} 50^{\prime} \mathrm{W}\end{array}$ & $600-800$ & $\begin{array}{c}\text { Agricultura, áreas de } \\
\text { pastoreio intensivo, } \\
\text { mato muito degradado }\end{array}$ & Ravinas; badlands. \\
\hline Ben Slimane & $\begin{array}{c}33^{\circ} 36^{\prime} \mathrm{N} \\
07^{\circ} 06^{\prime} \mathrm{W}\end{array}$ & $400-550$ & $\begin{array}{c}\text { Sobreiral, eucaliptal, } \\
\text { pastoreio }\end{array}$ & Erosão difusa \\
\hline
\end{tabular}

Foto l - Vista geral para a encosta sul da cordilheira do Rift ocidental (próximo de Ksar el Kebir), Novembro de 1998

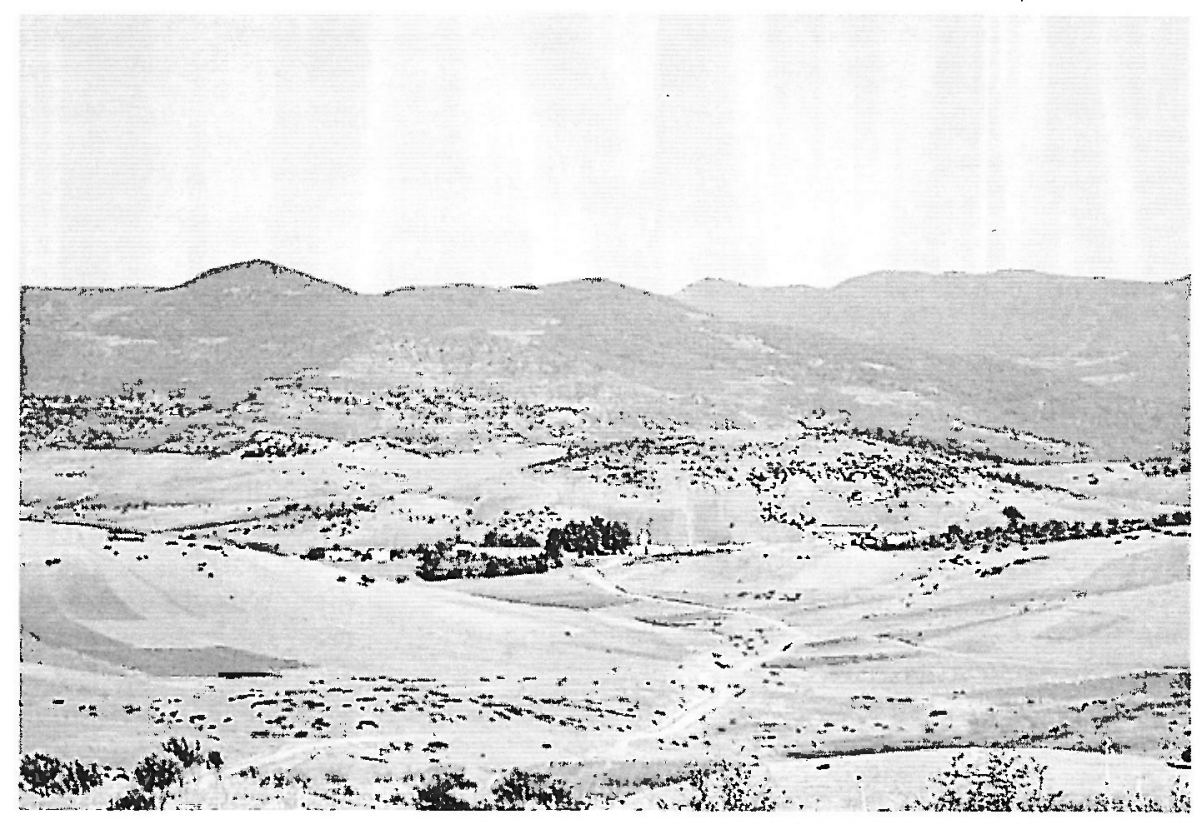

(1) Participam neste projecto: Universidade de Aveiro, Universidade de Barcelona, Universidade Politécnica de Madrid, Université Mohamed V, Marrocos, Institute National de Agronomique de Tunisie,Tunisia. 


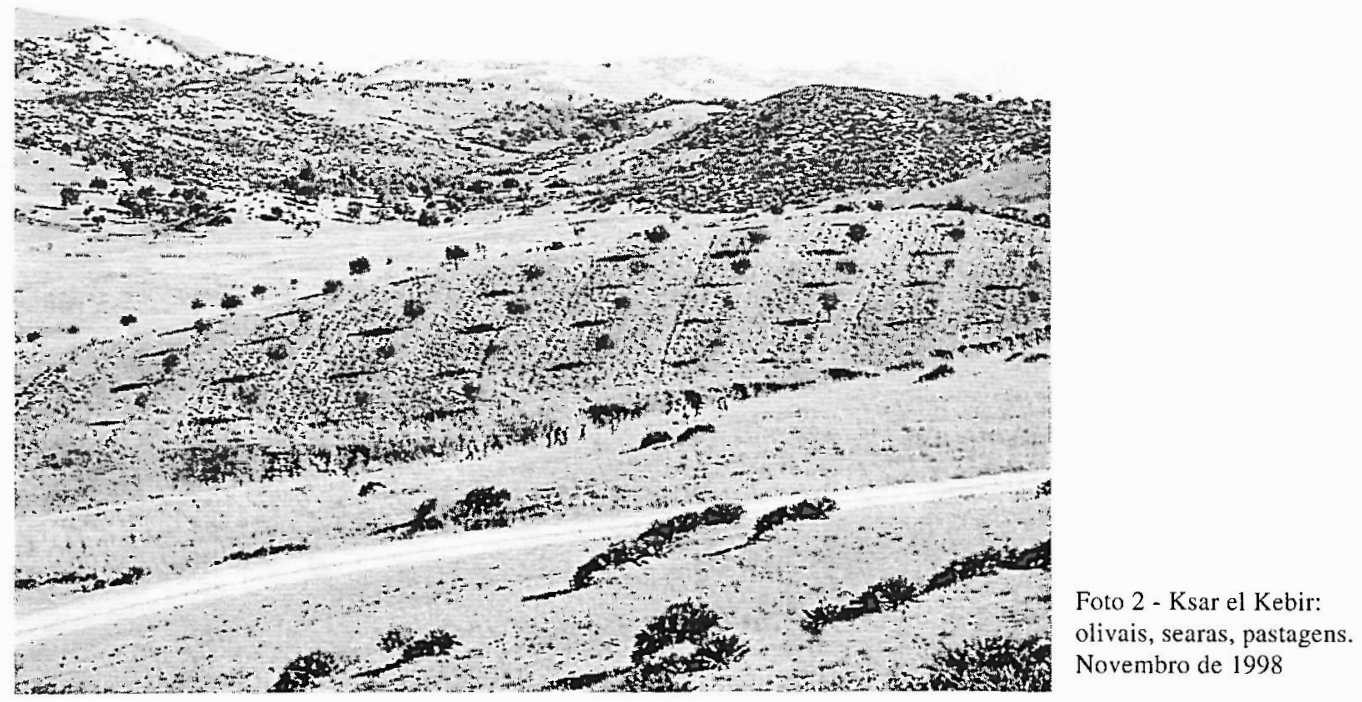

A estação seca dura 3 a 4 meses, sendo a temperatura média anual de $22^{\circ} \mathrm{C}$. Nas vertentes ocorrem sobreiros, pinheiros e cedros, e nas colinas margosas e gresosas o sobreiral está muito degradado e surgem os matos de urzes, estevas, lantisco, alfazema, medronheiros e zambujeiros.

Os usos do solo são a cultura de cereais e a pastoricia. A área possui uma forte pressão demográfica (Fotos 3 e 4 ).

\section{Ben Slimane}

O planalto de Ben Slimane localiza-se a $60 \mathrm{~km}$ a Sul de Rabat em declive suave para o Oceano Atlântico, com altitude compreendida entre os 175 e os 300 metros. É constituído por uma peneplanície xisto- quartzosa post-hercínica, atravessada por uma rede hidrográfica pouco incisa. Situado no andar bioclimatico semi-árido o planalto recebe em média 400 a $550 \mathrm{~mm}$ de chuva anualmente. Porém, na última década, choveu apenas entre os 250 e os $350 \mathrm{~mm}$ por ano, em média, o que motivou falta de água generalizada. Durante os períodos de seca, entre 6 a 7 meses, não há água suficiente nem para os homens, nem para os animais, e as plantas entram em stress hídrico.

Os solos siliciosos são delgados com capacidade fraca de retenção de água. $O$ sobreiral ocupa uma extensão de 12150 hectares; este povoamento que se encontra no seu limite climácico, ocupa os planaltos, associado a um sub-bosque de cistáceas, lantisco e alfazema, enquanto que, nas margens dos uedes, predomina a tuia (Foto 5).

No início deste século o planalto de Ben Slimane destinava-se essencialmente ao pastoreio dos rebanhos transumantes. $\mathrm{O}$ semi-nomadismo praticava-se com base na complementaridade entre as terras pobres a Norte da cidade de Ben Slimane es solos argilosos,
Foto 3 - Ksar el Kebir: pastagens, rebanhos, ravinas. Outubro de 1999

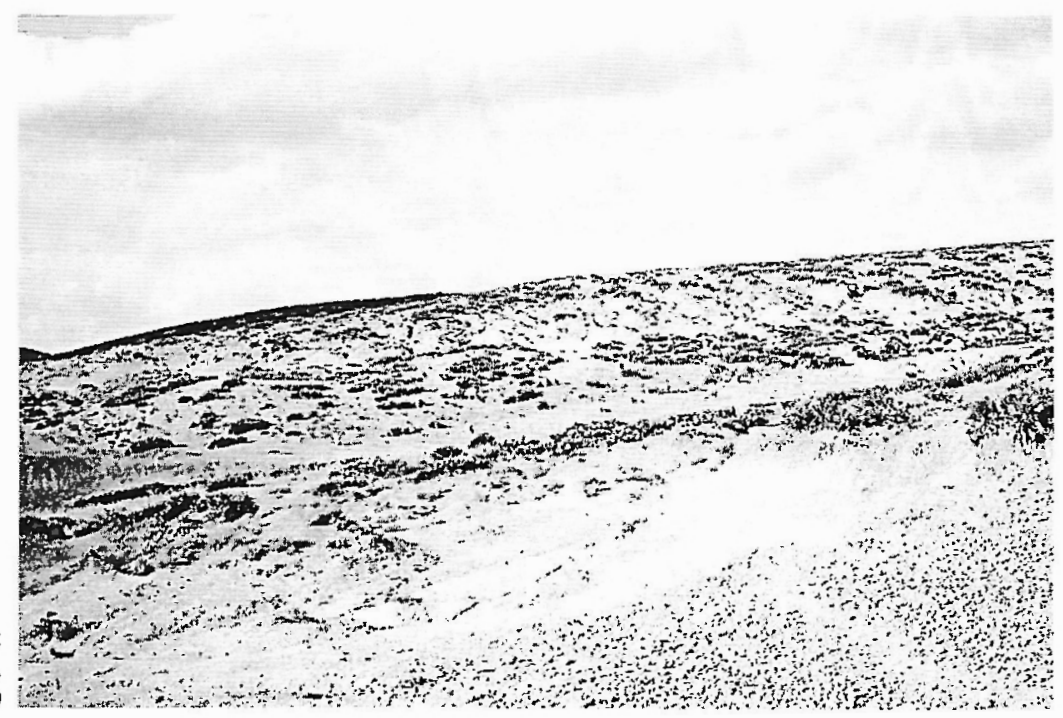




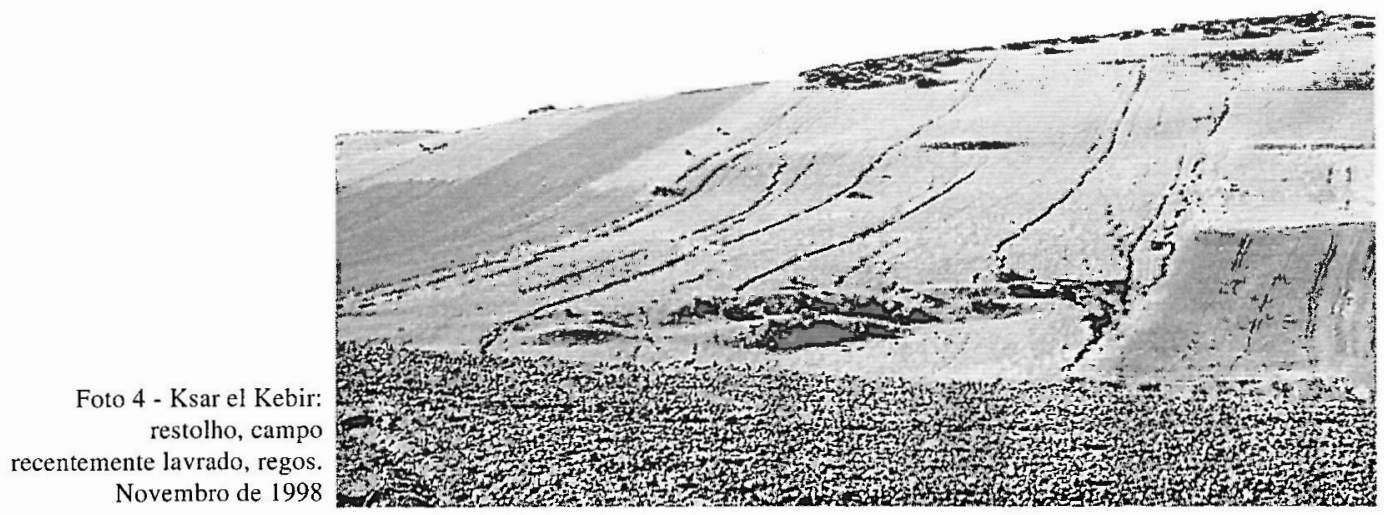

mais ricos, nos planaltos cultivados do interior. Os rebanhos deslocavam-se em distâncias pequenas, entre as duas áreas. As melhores terras eram semeadas no início do Inverno, quando os nómadas se dirigiam para as pastagens a Norte. Na Primavera e Verão eles regressavam para Sul, para a ceifa, e também para o pasto nos restolhos (REFFASS, 1980).

A partir de 1910, o Estado vendeu a sociedades europeias e a colonos grandes extensões de áreas agricolas e florestais, o que levou ao desaparecimento dos terrenos colectivos e de pastoreio. Surge então, próximo das cidades grandes, e nos sectores vizinhos do litoral, a agricultura comercial, assente em grandes explorações que se ocupam da cultura dos cereais (trigo), da vinha, e das hortaliças.

Em 1917, a mata de Ben Slimane torna-se «domínio público do Estado» tendo as populações vizinhas o direito de usofruto, para a recolha da lenha e da madeira, a apanha da bolota e o direito ao pastoreio de ovelhas e vacas (as cabras estavam proibidas).

Desde 1976 existe a obrigatoriedade de as colectividades locais investirem cerca de $20 \%$ das receitas provenientes da exploração florestal na reflorestação e na conservação das matas. Neste contexto, surgem 1700 hectares que foram reflorestados essencialmente com eucaliptos (Foto 6).

Os rebanhos têm aumentado significativamente nas últimas décadas e naturalmente os camponeses recorrem frequentemente ao pastoreio na mata. Desde o início da década de 90 , a regulamentação do direito de pastagem (reconhecido apenas para as populações residentes na proximidade da floresta) foi suprimido, para permitir às populações fazerem face aos efeitos da seca. Actualmente nãoé possível saber exactamente o número de efectivos pecuários que usam as pastagens, nas matas de Ben Slimane.

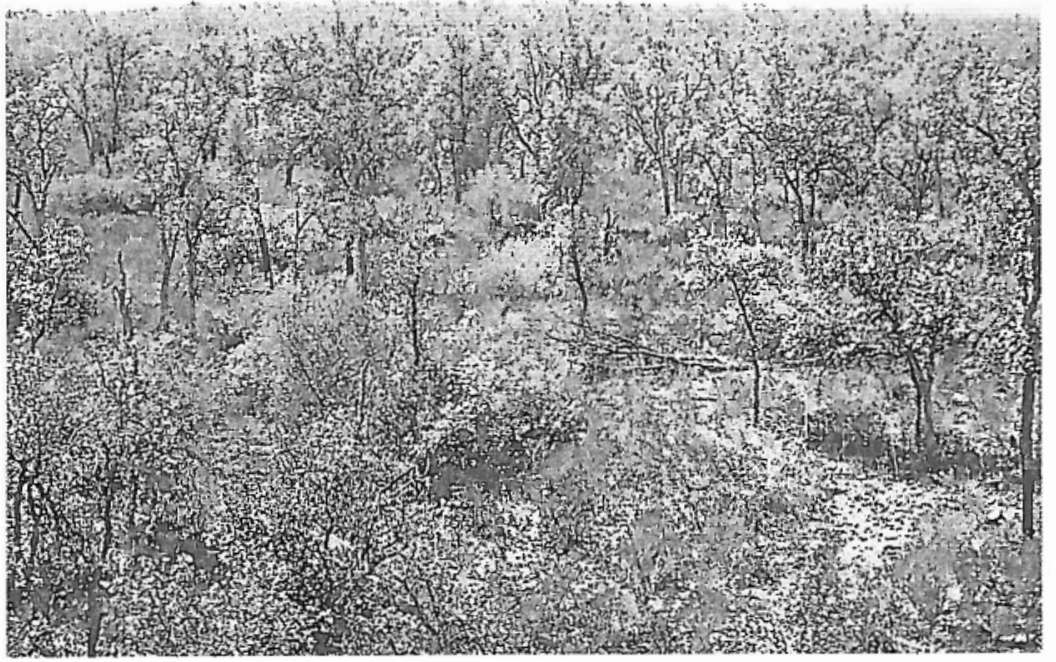

Foto 5 - Ben Slimane: sobreiral com pastoreio intensivo. Outubro de 1999 


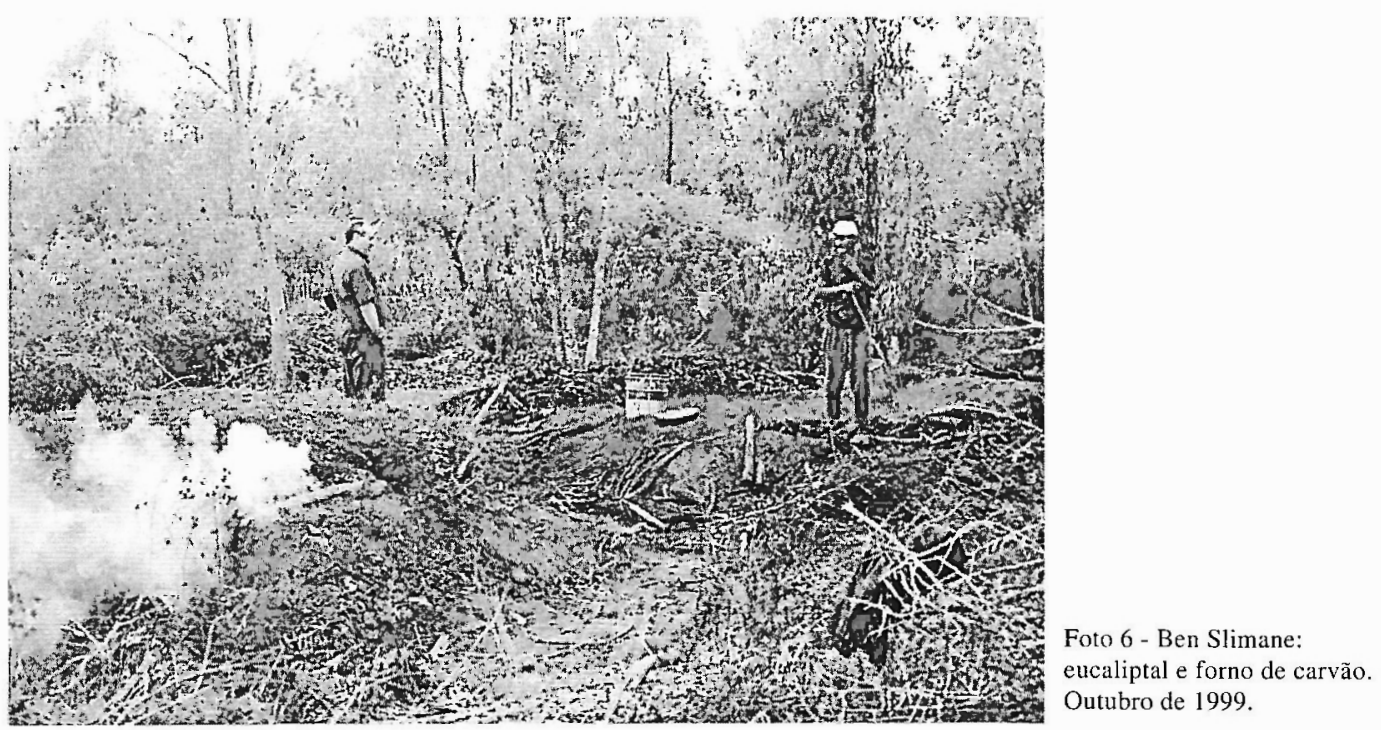

Apesar do êxodo rural para as cidades vizinhas (em $39 \%$ das famílias registou-se migração) a população da província de Ben Slimane tem aumentado continuamente (taxa de crescimento anual 1,7\%). É uma população jovem ( $25 \%$ da população tem menos de 7 anos idade), essencialmente rural (mais de 69\%) e com densidade elevada $\left(90 \mathrm{hab} / \mathrm{km}^{2}\right)($ ABDELLATIF, 1995).

\section{Simulações de chuva}

Foram efectuadas simulações de chuva em Marrocos, nos meses de Novembro e Dezembro de 1998. Os locais de amostragem foram escolhidos em função do uso do solo e das práticas de maneio a ele associadas. Foi utilizado o chuveiro e o protocolo descrito por CERDÀ et al. (1997). A intensidade da chuva durante o ensaio foi de $50,5 \mathrm{~mm} / \mathrm{h}$., durante 30 a 60 minutos. A escorrência foi medida no interior de uma parcela pequena, circular, de $0,24 \mathrm{~m}^{2}$, inserida cuidadosamente no solo. O caudal de escorrência à saída da parcela foi medido a intervalos de 5 minutos.

Determinou-se a textura do solo e a percentagem de matéria orgânica em amostras do solo colhidas nos locais dos ensaios (Quadro 2).

Na região de Ksarel Kibir realizaram-se simulações de chuva nas áreas agrícolas em pousio e com pastoreio, e nos matos com sobrepastoreio. Os valores daescorrência são bastante elevados desde 15 a $50 \%$ da chuva caída. As perdas de solo são enormes, atingindo valores médios de cerca de $173 \mathrm{~g} / \mathrm{h} / \mathrm{m}^{2}$, com máximos absolutos superiores a $275 \mathrm{~g} / \mathrm{h} / \mathrm{m}^{2}$ (Quadro 3).

Em Ben Slimane as simulações de chuva fizeram-se no sobreiral e ainda na plantação de eucalipto. Nas áreas de regeneração do sobreiro e do sub-bosque a capacidade de infiltração é elevada e a escorrência é quase inexistente. Nos solos sujeitos a pastoreio, pouco intenso, as perdas de solo são baixas $(1,3 \mathrm{~g} / \mathrm{h} /$ $\left./ \mathrm{m}^{2}\right)$, enquanto que nas áreas intensamente pastoreadas as perdas de solo são elevadas $\left(50 \mathrm{~g} / \mathrm{h} / \mathrm{m}^{2}\right)$ e a capacidade de infiltração dos solos é má, correspondendo a escorrência a mais de $20 \%$ da chuva caída. A plantação de eucaliptos acusa também escorrência relevante, mas as perdas de solo são menores (Quadro 3).

\section{Conclusão}

Em conclusão, nas encostas do Rift, a profusão de rebanhos que usam toda a pastagem disponível nos matagais degradados e nos restolhos dos cereais, intensifica os processos erosivos contemporâneos. Nos planaltos de Ben Slimane, cobertos por sobreiral, observa-se uma relação directa entre a intensidade do pastoreio, a cobertura do solo e as perdas de solo e a produção de escorrência.

Assim, nas áreas que mantêm o sistema de exploração tradicional (Ben Slimane), apesar da intensi-

Quadro 2 - Características dos solos

\begin{tabular}{|c|c|c|c|c|c|c|c|}
\hline & & \multirow{2}{*}{$\begin{array}{c}\text { Densidade } \\
\text { do solo } \\
\text { g.cm-3 }\end{array}$} & \multirow{2}{*}{$\begin{array}{c}\text { Matéria } \\
\text { orgânica }(\%)\end{array}$} & \multicolumn{4}{|c|}{ Textura } \\
\hline & & & & $\begin{array}{c}>2 \mathrm{~mm} \\
(\%)\end{array}$ & $\begin{array}{c}\text { Areia } \\
(\%)\end{array}$ & $\begin{array}{c}\text { Silte } \\
(\%)\end{array}$ & $\begin{array}{c}\text { Argila } \\
(\%)\end{array}$ \\
\hline Ksar el Kebir & Med. & 1,0 & 7,5 & 1,3 & 10,6 & 52,5 & 34,8 \\
\hline Ben Slimane & Med. & 1,2 & 8,2 & 34 & 48,0 & 13,2 & 4,8 \\
\hline
\end{tabular}


Quadro 3 - Cobertura do solo, escorrência e taxas de erosão

\begin{tabular}{|c|c|c|c|c|c|}
\hline & & $\begin{array}{l}\text { Cobertura } \\
\text { por } \\
\text { vegetação } \\
(\%)\end{array}$ & $\begin{array}{c}\text { Cobertura } \\
\text { por manta } \\
\text { morta } \\
(\%)\end{array}$ & $\begin{array}{l}\text { Escorrência } \\
\text { (\% Precipi- } \\
\text { tação) }\end{array}$ & $\begin{array}{c}\text { Taxa de } \\
\text { erosäo } \\
\left(\mathrm{g} / \mathrm{h} / \mathrm{m}^{2}\right)\end{array}$ \\
\hline \multicolumn{6}{|c|}{ Ksar el Kebir (Alcacer Quibir) } \\
\hline $\begin{array}{l}\text { Solos agrícolas com } \\
\text { pastorícia intensiva }\end{array}$ & $\begin{array}{l}\text { Max. } \\
\text { Média } \\
\text { Min. }\end{array}$ & $\begin{array}{c}30 \\
19,4 \\
0 \\
\end{array}$ & $\begin{array}{c}10 \\
3,8 \\
0\end{array}$ & $\begin{array}{c}56,3 \\
24,5 \\
0\end{array}$ & $\begin{array}{c}71.3 \\
27,6 \\
0\end{array}$ \\
\hline Áreas de pastoreio intensivo & $\begin{array}{l}\text { Max. } \\
\text { Média } \\
\text { Min. }\end{array}$ & $\begin{array}{r}60 \\
31,7 \\
0\end{array}$ & $\begin{array}{r}5 \\
3,3 \\
0\end{array}$ & $\begin{array}{c}29,2 \\
15,4 \\
0\end{array}$ & $\begin{array}{c}276,3 \\
173,6 \\
0 \\
\end{array}$ \\
\hline \multicolumn{6}{|c|}{ Ben Slimane } \\
\hline $\begin{array}{l}\text { Sobreiros com pastoreio } \\
\text { pouco intenso }\end{array}$ & $\begin{array}{l}\text { Max. } \\
\text { Média } \\
\text { Min. }\end{array}$ & $\begin{array}{r}40 \\
23,5 \\
10 \\
\end{array}$ & $\begin{array}{l}100 \\
97 \\
90 \\
\end{array}$ & $\begin{array}{c}17.8 \\
7 \\
0 \\
\end{array}$ & $\begin{array}{c}1,3 \\
\mathbf{0 , 4} \\
0 \\
\end{array}$ \\
\hline $\begin{array}{l}\text { Sobreiros com pastoreio } \\
\text { elevado. }\end{array}$ & $\begin{array}{l}\text { Max. } \\
\text { Média } \\
\text { Min. } \\
\end{array}$ & $\begin{array}{r}20 \\
17,5 \\
15 \\
\end{array}$ & $\begin{array}{r}32,5 \\
30,8 \\
30 \\
\end{array}$ & $\begin{array}{c}33,3 \\
20,8 \\
0 \\
\end{array}$ & $\begin{array}{c}85,3 \\
\mathbf{5 0 , 7} \\
0 \\
\end{array}$ \\
\hline Sobreiros regenerados & $\begin{array}{l}\text { Max. } \\
\text { Média } \\
\text { Min. } \\
\end{array}$ & $\begin{array}{r}75 \\
66,7 \\
50 \\
\end{array}$ & $\begin{array}{c}82,5 \\
\mathbf{5 0 , 8} \\
0 \\
\end{array}$ & $\begin{array}{l}0 \\
0 \\
0 \\
\end{array}$ & $\begin{array}{l}0 \\
\mathbf{0} \\
0 \\
\end{array}$ \\
\hline Plantação de eucaliptos & $\begin{array}{l}\text { Max. } \\
\text { Média } \\
\text { Min. }\end{array}$ & $\begin{array}{c}30 \\
10 \\
0\end{array}$ & $\begin{array}{r}85 \\
83,3 \\
80 \\
\end{array}$ & $\begin{array}{c}32,1 \\
23,6 \\
18,1\end{array}$ & $\begin{array}{l}3,7 \\
2,7 \\
2,0 \\
\end{array}$ \\
\hline
\end{tabular}

ficação da exploração, os riscos de erosão são pouco elevados. Nas áreas onde os sistemas tradicionais silvo-pastoris foram substituídos por cerealicultura, culturas arvenses e pastoreio intensivo, o risco de erosão é muito forte (Ksar el Kebir).

\section{Agradecimentos}

Os autores manifestam o seu agradecimento ao Programa INCO-DC da Comunidade Europeia pelo financiamento do projecto de investigação ERBIC18-CT97-0147MEDCHANGE - "Os efeitos das mudanças no uso da terra e nas técnicas de maneio em sistemas agro-silvo-pastoris, sobre os processos de degradação do solo"

\section{Bibliografia}

ABDELLATIF, K. (1995) - La fôret entre la gestion forestière et l'utilisation par les populations riveraines - cas de la fôret de Ben Slimane. Mémoire pour l'obtention du diplôme d'Études Superieurs en Aménagement et Urbanisme, Rabat.

BEN ATTOU, M. (1992) - Larache et Ksar El Kébir: leur rôle dans l'organisation régionale. Doctorat en géographie. Université François Rabelais, Tours, Tome I.

Carte des sols du Maroc. Division de la Cartographie, Direction de la Conservation Foncière, du Cadastre et de la Cartographie (1996).

CARVALHO, T.M.M., COELHO, C.O.A., FERREIRA, A.J.D., Laouina, A., NAAFA, R., HAMZA, A. (1999) - "MEDCHANGE: Os efeitos das mudanças no uso da terra e nas técnicas de maneio em sistemas agro-silvo-pastoris, sobre os processos de degradação do solo. Processos hidrológicos $\mathrm{e}$ erosivos decorrentes dos usos do solo e técnicas de maneio". Actas, VIII Colóquio Ibérico de Geografia, Vol. I, p. 95-103.
CERDÀ, A.; IBAÑEZ, S. and CALVO, A. (1997) - "Design and operation of a small and portable rainfall simulator for rugged terrain". Soil Technol., 11 (2), p. 161-168.

COELHO, C., SALA, M., DEL TANÁGO, M., LAOUINA, A., HAMZA, A. $(1998,1999)$ - Effects of land use and land management practices changes on land degradation under forest and grazing ecosystems. First Year Report. Contract ERBIC18-CT97-0147. European Commission - INCO DC.

CONACHER, A. and SALA, M. (1998) - Land degradation in mediterranean environments of the world: nature and extent, causes and solutions. John Wiley and Sons, England.

FERREIRA, A.J.D., COELHO, C.O.A., WALSH, R.P.D, SHAKESBY, R.A. , CEBALLOS, A. e DOERR, S.H. (2000) - "Hydrological implications of soil water-repellency in Eucalyptus globulus forests, north-central Portugal". Joumal of Hydrology, 231-232, p. 165-177.

LAOUINA, A. (1999) - "The participation of the rural population, condition for the success of interventions in mountains. The case of the Rif and pre-Rif slopes, Morocco". Proceedings of the International Seminar on Land Degradation and Desertification, 24th-30th August, Évora, p.101-106.

Maroc Forestier. Division de la Cartographie, Direction de la Conservation Foncière, du Cadastre et de la Cartographie.

MIKESELL, M.W. (1960) - "Deforestation in Northern Morocco". Science, Vol. 132, (3425), p. 441-448.

Précipitations Annuelles. Atlas du Maroc, Planche no 4, Comité de Géographie du Maroc.

Rapport de l'Aménagement de la Fôret d'Ahl Sherif( 1978-1998). Direction desEaux et Fôrets/SCET. Service de l' Aménagement et de l'Inventaire. Rabat.

REFFASS, A . (1980)-Région de Ben Slimane: étude de géographie humaine. Mémoire de 3éme cycle, Faculté des Lettres et Sciences Humaines, Rabat. 